\title{
Estudio químico y etnobotánico de Croton leptostachyus
}

\author{
Daniel Andrés Pardo-Rodriguez ${ }^{1,2}$, Lesly Tatiana Ortíz-Romero ${ }^{1,2}$, Aura Lorena Tacha ${ }^{1,3}$, Elizabeth Murillo-Perea ${ }^{1,2, *}$, \\ Jhon Jairo Mendez-Arteaga ${ }^{1,2}$, Walter Murillo-Arango ${ }^{1,2}$ \\ ${ }^{1}$ Grupo de Investigación en Productos Naturales, GIPRONUT, Departamento de Química, \\ Facultad de Ciencias Básicas, Universidad del Tolima, Ibagué, Colombia \\ ${ }^{2}$ Departamento de Química, Facultad de Ciencias Básicas, Universidad del Tolima, Ibagué, Colombia \\ ${ }^{3}$ Facultad de Medicina Veterinaria y Zootecnia, Universidad del Tolima, Ibagué, Colombia
}

\begin{abstract}
Resumen
En este estudio se estableció el uso tradicional que la comunidad del municipio de Gigante, Huila, da a la especie vegetal Croton leptostachyus, llamada comúnmente “mosquero”. Igualmente, se confrontó la información obtenida con el estudio fitoquímico de la planta. Se seleccionaron diez veredas, situadas entre los 0 y los $1.200 \mathrm{msnm}$, en las que se aplicó el instrumento estadístico y se recolectó el material vegetal utilizado en la determinación de los principales grupos de metabolitos secundarios, así como de la bioactividad. Se encontró que C. leptostachyus bioacumula fitofenoles, saponinas y carbohidratos en sus estructuras vegetales: las hojas parecen ser centros de acopio, principalmente de compuestos de naturaleza terpénica, saponósidos y flavonoides, en tanto que la raíz es bioacumuladora de iridoides y alcaloides. El etanol resultó ser el solvente más adecuado para extraer los fitoconstituyentes. Bajo las condiciones aplicadas, los extractos de la planta no evidenciaron actividad frente a las bacterias Escherichia coli, Klebsiella pneumoniae, Salmonella tiphymurium, Staphylococcus aureus y la levadura Candida albicans; sin embargo, el extracto etanólico del tallo inhibió el crecimiento de Fusarium oxysporum en un $58,6 \%$ en $10.000 \mathrm{mg} / \mathrm{l}$, y el de la raíz en un 97,5\%. Por otra parte, el extracto etanólico del tallo y de la raíz inhibió de manera apreciable el crecimiento radial de Aspergillus niger, con concentraciones inhibitorias $\left(\mathrm{CI}_{50}\right)$ de $11.883 \pm$ 1.132 y de $935 \pm 30 \mathrm{mg} / \mathrm{l}$, respectivamente, observándose daños incluso en las estructuras fúngicas.
\end{abstract}

Palabras claves: Croton leptostachyus, mosquero, etnobotánica, metabolitos secundarios, bioactividad.

\section{Chemical and ethnobotanical study of Croton leptostachyus}

\begin{abstract}
In this study we established the traditional use given by the community of the municipality of Gigante, Huila, Colombia, to the plant species Croton leptostachyus, known by the common name of "mosquero". We also checked the information from the phytochemical study of the plant. Ten villages located between 0 and 1200 MASL were selected to implement the statistical tool, as well as to collect plant material used in the determination of the major groups of secondary metabolites and bioactivity. We found that C. leptostachyus bioaccumulates phytophenols, saponins and carbohydrates in the different plant structures: Leaves appear to be collection centers mainly of terpenoid, flavonoid and saponin compounds while the root bioaccumulates iridoids and alkaloids. Ethanol was the most suitable solvent to extract the phytoconstituents. The plant extracts did not show activity against the bacteria species Escherichia coli, Klebsiella pneumoniae, Salmonella stiphymurium, Staphylococcus aureus and the yeast Candida albicans; however, the ethanol extract of the stem inhibited the growth of Fusarium oxysporum by $58.6 \%$ to $10,000 \mathrm{mg} / \mathrm{L}$, and the root extract by $97.5 \%$. On the other hand, the ethanol extract of the stem and root significantly inhibited the radial growth of Aspergillus niger, with inhibitory concentration $\left(\mathrm{IC}_{50}\right)$ of 11,883 $\pm 1,132$ and $935 \pm 30$ $\mathrm{mg} / \mathrm{L}$, respectively, and caused damage even in the fungal structures.
\end{abstract}

Key words: Croton leptostachyus, mosquero, ethnobotany, secondary metabolites, bioactivity.

\section{Introducción}

El acervo de conocimientos de las comunidades resulta de gran valor científico a la hora de evaluar el patrimonio cultural de una región, así como para la consolidación del saber científico.
Los estudios etnobotánicos suelen centrarse en los grupos humanos cuya relación con la naturaleza es más directa, tales como los pueblos indígenas y las culturas rurales, cuyo acceso a la medicina tradicional se dificulta por múltiples y diferentes razones (Pardo \& Gómez, 2003). 
Colombia, especialmente en la zona sur, constituye un ejemplo evidente de ello, pues allí las prácticas tradicionales, costumbres y conocimientos sobre el uso de sus recursos florísticos continúa siendo parte del diario vivir. No obstante, hoy estas actividades se encuentran en riesgo de desaparecer, dado que los cambios socioculturales y el poco interés en las tradiciones que las nuevas generaciones muestran al adoptar hábitos ajenos al lugar, interrumpe la transmisión de los conocimientos, perdiéndose así gran parte de este rico patrimonio legado de nuestros antepasados (RodríguezEcheverry, 2010).

El uso de plantas medicinales sigue siendo parte importante de las investigaciones en farmacología humana y animal, puesto que estas proporcionan alternativas de bajo costo para el tratamiento de múltiples enfermedades y tienen, además, un gran potencial para el desarrollo sostenible. A ello se añade el creciente interés por el desarrollo de nuevos antisépticos y agentes antimicrobianos para el tratamiento de infecciones (Weckesser, et al., 2007), lo cual ha propiciado la búsqueda de métodos alternativos, tales como la selección de razas resistentes, el uso de vacunas y extractos de plantas, y el control biológico(Rosado-Aguilar, et al., 2008).

Sin embargo, se ve con preocupación que muchos de los mecanismos de control no son eficientes frente a los patógenos, de ahí el aumento de la resistencia de bacterias, parásitos e insectos a los antibióticos e ixodicidas, entre otros, lo que se ha convertido en un problema cada vez más generalizado para la industria de producción animal (Weckesser, et al., 2007). Tradicionalmente, las plantas propias de cada zona geográfica se han empleado con diferentes fines medicinales. El retorno al uso de vegetales como fuente de compuestos bioactivos más seguros para el medio ambiente, los animales y la salud humana, parece inminente. A pesar de esto, del total de la masa natural que ofrece el planeta, muy pocas plantas se han evaluado, por lo que las perspectivas de la investigación en este campo son grandes (Mansaray, 2000).

El presente trabajo se desarrolló a partir de la información obtenida sobre la especie Croton leptostachyus, planta conocida comúnmente como "mosquero", la cual es ampliamente utilizada por pequeños productores de la subregión huilense de Colombia en el tratamiento de enfermedades asociadas a bacterias y hongos. Mediante una dinámica de investigación insertada en la comunidad, se logró la identificación de conocimientos tradicionales, que luego se verificaron a través de la determinación in vitro de la actividad biológica antibacterial y antifúngica de C. leptostachyus, así como de la cualificación de los metabolitos secundarios.

\section{*Correspondencia:}

Elizabeth Murillo Perea, emurillo8@hotmail.com

Recibido: 12 de septiembre de 2014

Aceptado: 20 de noviembre de 2014

\section{Materiales y métodos}

\section{Área de estudio}

La recolección de la información etnobotánica y de la muestra vegetal, se hizo en el municipio de Gigante, perteneciente a la subregión centro del departamento del Huila, en la región andina colombiana, cuya posición astronómica corresponde a $2^{\circ} 23^{\prime} 23^{\prime \prime}$ de latitud norte y $75^{\circ} 33^{\prime}$ de longitud oeste (Alcaldía de Gigante, Huila). Según el censo del DANE (2005), el municipio de Gigante cuenta con 28.174 habitantes, aproximadamente, de los cuales 13.857 habitan en la zona rural, distribuidos en cinco corregimientos y 50 veredas. Para la realización de la investigación se contó con la participación activa de la comunidad de diez veredas situadas entre 0 y $1.200 \mathrm{msnm}$ (en las cuales crece la planta según la Red Nacional de Jardines Botánicos, 2008). Las veredas seleccionadas fueron Gran Vía, El Tendido, Vueltas Arriba, La Guandinosa, El Rodeo-Recreo, El Mesón, Río Loro, Matambo, Potrerillo y Pueblo Nuevo. La información etnobotánica se recopiló entre octubre y noviembre de 2011; se entrevistó a un total de 180 personas (89\% correspondió a hombres y $11 \%$ a mujeres), con edades comprendidas entre los 28 y 55 años, que se desempeñaban en labores de campo, de mayordomía, ganadería, administración y en oficios varios en las fincas visitadas. Después de obtener el consentimiento de los entrevistados, se formularon las preguntas diseñadas según los parámetros propuestos por Vàlles (1996), utilizando, además, fichas etnobotánicas basadas en el estudio llevado a cabo por Gil, Mejía, Carmona y Rodríguez (2003).

El propósito de la indagación fue recolectar información acerca de las aplicaciones medicinales de la planta bajo estudio, y obtener una explicación detallada que permitiera conocer la parte vegetal utilizada, la forma de tratamiento, la dosificación y la frecuencia de uso.

\section{Secado y preparación de extractos}

El material vegetal se recolectó en la finca Los Cauchos $\left(31^{\circ} \mathrm{C}, 850 \mathrm{msnm}\right)$, localizada en el municipio de Gigante; se depositó una muestra en el herbario Toli de la Universidad del Tolima en Ibagué, bajo el número de colección 009586, para su descripción y determinación taxonómica.

El material vegetal se secó en una estufa a una temperatura de $50{ }^{\circ} \mathrm{C}$ durante 48 horas y, posteriormente, se trituró y tamizó (2 micras). Las hojas, los tallos y la raíz así tratados se pusieron separadamente en un extractor Soxhlet, utilizando como solventes de extracción agua y etanol (relación 1:10 de material vegetal/solvente) durante 8 horas; los extractos obtenidos se almacenaron a $5{ }^{\circ} \mathrm{C}$ en frascos debidamente rotulados. Cada uno de los extractos se estandarizó mediante la determinación de los índices farmacognósticos y la caracterización fitoquímica, observando los estándares de calidad (Bruneton, 1991; WHO, 1998). 


\section{Tamizaje fitoquímico}

Se siguió la metodología recomendada por Sanabria (1983) y Lock (1994), la cual consiste en una serie de técnicas de separación y purificación, y en ensayos a la gota cuyo objetivo es comprobar los principales núcleos de metabolitos secundarios presentes en los diferentes extractos.

\section{Actividad antimicrobiana}

El efecto de los extractos en las cepas de E. coli, K. pneumoniae, S. tiphymurium y $S$. aureus se estableció mediante el método de pozos en agar Mueller Hinton (Cona, 2002). Una vez inoculado el medio con los microorganismos $\left(1 \times 10^{8}\right.$ $\mathrm{UFC} / \mathrm{ml}$ ), se dispusieron tres perforaciones en el medio sólido de $0,5 \mathrm{~cm}$ cada una, en las cuales se sirvieron 0,25 $\mathrm{ml}$ del extracto en concentraciones conocidas (500-10.000 $\mathrm{mg} / \mathrm{l})$. Las placas se incubaron a $37^{\circ} \mathrm{C}$ durante 24 horas, al término de las cuales se evaluaron los resultados mediante la lectura del diámetro de inhibición del halo del crecimiento (en milímetros) de los microorganismos. Todos los ensayos se realizaron por triplicado.

\section{Actividad antifúngica}

Se aplicó el método de inhibición zonal en agar de papa y dextrosa (Potato Dextrose Agar, PDA) (Torres, 2005), servido en cajas de Petri previamente esterilizadas. Se probaron diferentes diluciones de los extractos con diferentes concentraciones (500-10.000 mg/l) y, posteriormente, se dispuso un disco $(0,5 \mathrm{~cm})$ con los micelios de las especies $F$. oxysporum y A. niger. Las cajas de Petri con su contenido se incubaron a $30{ }^{\circ} \mathrm{C}$ hasta que la base del hongo cubrió todo el diámetro del recipiente que contenía el control negativo (medio de cultivo), el cual fue la base de comparación en el cálculo del área de inhibición de las muestras. Con esta información se calculó la $\mathrm{CI}_{50}(\mathrm{mg} / \mathrm{l})$. El efecto inhibitorio sobre la levadura $C$. albicans se estableció mediante la misma metodología de pozos descrita para las bacterias, pero en agar Sabouraud a $37{ }^{\circ} \mathrm{C}$.

\section{Análisis estadístico}

Los resultados se analizaron a partir de la media de tres determinaciones para cada nivel de la concentración aplicada en todos los ensayos. El análisis de la varianza permitió comparar la actividad entre concentraciones y entre extractos con un nivel de confianza del $95 \%$. Para las comparaciones múltiples se utilizó la prueba de la mínima diferencia significativa (DSM).

\section{Resultados y discusión}

Entre octubre y noviembre de 2011 se entrevistó a un total de 180 personas asentadas en diez veredas del municipio de Gigante, Huila, las cuales se seleccionaron de acuerdo al rango de crecimiento de la planta. El número de encuestados según las veredas fue el siguiente: en Potrerillos, 30 personas; en El Tendido, Pueblo Nuevo, Río Loro, Vueltas Arriba y La Guandinosa, 20 personas por vereda; en Gran Vía y Matambo, 15 personas en cada una, y en Rodeo-Recreo y El Mesón, 10 personas por vereda. El $89 \%$ de los encuestados correspondió al género masculino y el $11 \%$, al femenino; la edad osciló entre los 28 y 55 años. Un $56 \%$ dijo dedicarse a las labores de campo; el $28 \%$ afirmó desempeñarse en la administración de la hacienda; un $5 \%$ se ocupaba en oficios varios, y un $3 \%$ manifestó dedicarse a la ganadería. Los encuestados afirmaron conocer la planta con los nombres de mosquerillo (45\%), escoba (22\%), mosquero (17\%), yerba amarga (8\%), sangregado (7\%) y montesina (1\%).

En la tabla 1 se consignan los usos más comunes dados a la planta, observándose claramente que el vegetal tiene gran aplicación en el tratamiento de enfermedades en animales

Tabla 1. Usos dados a Croton leptostachyus (mosquero) por la comunidad campesina de Gigante, Huila, Colombia

\begin{tabular}{|c|c|c|c|c|c|c|}
\hline \multicolumn{7}{|c|}{ Usos etnobotánicos } \\
\hline Vereda & Alimenticio & Artesanal & En animales & Medicinal & Ornamental & Forraje \\
\hline Gran Vía & - & - & 4 & 8 & 3 & - \\
\hline El Tendido & - & - & 9 & 7 & 2 & 2 \\
\hline Vueltas Arriba & - & - & 5 & 10 & 5 & - \\
\hline La Guandinosa & - & - & 11 & 3 & 5 & 1 \\
\hline Rodeo-Recreo & - & 2 & 5 & 1 & 2 & - \\
\hline Potrerillos & 2 & - & 17 & 8 & 2 & 1 \\
\hline Mesón & - & 3 & 5 & 1 & 1 & - \\
\hline Río Loro & - & - & 12 & 6 & 2 & - \\
\hline Matambo & - & - & 5 & 5 & 5 & - \\
\hline Pueblo Nuevo & 1 & - & 11 & 3 & 5 & - \\
\hline Totales & 3 & 5 & 84 & 52 & 32 & 4 \\
\hline
\end{tabular}


Tabla 2. Uso medicinal, parte utilizada, modo de empleo, dosificación y frecuencia de uso de Croton leptostachyus por parte de la comunidad campesina de Gigante, Huila, Colombia

\begin{tabular}{|c|c|c|c|c|c|}
\hline Enfermedad & $\%$ & Parte utilizada & Modo de empleo & Dosificación & Frecuencia de uso \\
\hline Ulcera gástrica (humanos) & 2 & Hojas & Infusión & Puñado & Anual \\
\hline Sarna (bovinos, caninos) & 7 & Toda la planta & Maceración & Baños (5 l) & Mensual \\
\hline Miasis (enfermedad parasitaria) & 5 & Toda la planta & Emplastos & Tanteo & Diario \\
\hline Cólicos (humanos, caninos, caprinos) & 3 & Hojas & Infusiones & Puñado & Anual \\
\hline Diabetes & 2 & Hojas & Decocción & Puñado & Anual \\
\hline Repelente de moscas & 28 & Toda la planta & Maceración & Baños (5 l) & Semanal \\
\hline Alopecia & 2 & Hojas & Zumo & Tanteo & Anual \\
\hline Mezquinos, papilomas & 19 & Látex - hojas & Frotamiento & Tanteo & Diario \\
\hline Alergias, salpullido, brotes de piel & 8 & Toda la planta & Maceración & Baños $(500 \mathrm{ml})$ & Diario \\
\hline No sabe, no responde & 24 & --- & --- & --- & --- \\
\hline
\end{tabular}

$(46,6 \%)$ y en humanos $(28,8 \%)$, aunque también es utilizado como especie ornamental $(17,7 \%)$.En la tabla 2 se agrupan los procesos aplicados para alcanzar los beneficios de la planta, la parte del vegetal que se maneja y las dosis o proporción aplicada en cada caso. En concordancia con los datos contenidos en la tabla 1 , un mayor porcentaje de personas utilizaba la planta en el control de enfermedades básicas, tanto en animales como en humanos, es decir, como repelente de insectos (28\%), y para el tratamiento de cólicos, úlceras, papilomas, alergias, brotes de piel y otros (32\%).

El proceso de preparación, la dosis y la frecuencia de uso de la planta varían y parecen depender del sujeto que la aplique; no obstante, el agua como solvente y la maceración, seguida de la decocción o la preparación de una infusión suelen ser los mecanismos más frecuentes para extraer los principios activos de la especie vegetal.

De acuerdo a lo manifestado por los encuestados, los conocimientos etnoculturales les habían sido transmitidos oralmente por sus padres (35\%), y en menor proporción, de forma escrita $(10 \%)$. Sin embargo, el $55 \%$ declaró que aprendió a utilizar la planta a través de amigos o compañeros de trabajo. El 96 \% manifestó que como forma de agradecer el conocimiento adquirido, lo retransmitían a las nuevas generaciones. Dicho conocimiento ha podido persistir hasta hoy a pesar de que muchos jóvenes no muestran un interés real en el uso de prácticas complementarias en veterinaria y en las labores del campo. Se determinó que los saberes sobre la planta estaban fuertemente ligados a los hombres mayores de 25 años, quienes representaban más del 75\% de los encuestados.

\section{Estudio fitoquímico}

En la tabla 3 se pueden apreciar los resultados obtenidos mediante el tamizaje fitoquímico de los extractos de hojas, tallos y raíz. Se detectaron carbohidratos, saponinas, terpenos, esteroides y polifenoles en relativa abundancia en tallos, hojas y raíz, aunque los carbohidratos reductores, el material saponósido y los compuestos de naturaleza terpénica o esteroidal se acumularon preferiblemente en las hojas de la planta; el etanol pareció ser el solvente adecuado para extraerlos.

Los tallos y las hojas mostraron ser buenos reservorios de metabolitos de naturaleza fenólica: polifenoles en general, fenilpropanoides y flavonoides, constituyendo estos el tipo de compuestos de mayor variabilidad y abundancia en $C$. leptostachyus. A pesar de que los iridoides se detectaron en todas las partes vegetales analizadas, la mayor cantidad se encontró en la raíz. Los únicos fitocompuestos encontrados en abundancia en la raíz de la planta y bajo las condiciones del ensayo fueron los alcaloides.

Debe reconocerse, sin embargo, que establecer la presencia (no así la ausencia) de un determinado núcleo, tiene dificultades debido a que las pruebas con reactivos cromógenos pueden no ser lo suficientemente sensibles. La variación entre órganos, edad del vegetal, temporada de cosecha, ubicación geográfica y en la polaridad del solvente extractor, podría constituir una restricción adicional.

Pese a que los carbohidratos no pertenecen al grupo de metabolitos secundarios, su detección se justifica si se tiene en cuenta que desempeñan un papel ecológico importante en la relación planta-animal y porque, además, muchos de ellos se disponen en forma de glicósidos en el citoplasma (fenoles, cardiotónicos, saponinas y antocianinas, entre otros). Cuando los constituyentes activos de la planta se encuentran en esta forma, la pérdida de la fracción glicosídica afecta la bioactividad del producto vegetal (Bruneton, 1991).

Por otra parte, se han reportado los efectos benéficos de los compuestos de naturaleza fenólica (antocianinas, flavonoles, fenilpropanoides, ácidos fenólicos, etc.) en algunos padecimientos degenerativos, por ejemplo, en las enfermedades cardiovasculares (Shanmuganayagam, et al., 2007; Falchi, 
Tabla 3. Tamizaje fitoquímico de los diferentes órganos de la planta

\begin{tabular}{|c|c|c|c|c|c|}
\hline \multirow{2}{*}{ Metabolitos } & \multirow{2}{*}{ Reactivo cromógeno } & \multicolumn{3}{|c|}{ Etanol } & \multirow{2}{*}{$\begin{array}{c}\text { Agua } \\
\text { Hoja }\end{array}$} \\
\hline & & Tallo & Hoja & Raíz & \\
\hline \multirow{2}{*}{ Carbohidratos } & Molisch & + & + & + & +++ \\
\hline & Benedict & ++ & +++ & + & +++ \\
\hline Saponinas & Rosenthaler & + & +++ & ++ & + \\
\hline Polifenoles & Folin-Ciocalteu (FC) & ++ & ++ & + & ++ \\
\hline \multirow{2}{*}{ Taninos } & Cloruro férrico & + & ++ & + & +++ \\
\hline & Gelatina-sal & + & + & ND & ND \\
\hline Flavonoides & Shinoda & + & ++ & ND & ND \\
\hline Fenilpropanos & Arnow & + & + & - & ++ \\
\hline Antraquinonas & Bornträger & ND & ND & ND & ND \\
\hline Anillo esteroidal & Lieberman-Burchard & ND & ++ & ++ & ND \\
\hline Terpenos & Salkowski & + & +++ & + & + \\
\hline Iridoides & Vainillina metanólica & + & ++ & +++ & + \\
\hline \multirow{5}{*}{ Alcaloides } & Tanred & ND & ND & ++ & ND \\
\hline & Dragendorff & ND & ND & ++ & ND \\
\hline & Mayer & ND & ND & ++ & ND \\
\hline & Ehrlich & ND & ND & ++ & ND \\
\hline & Valser & ND & ND & ++ & ND \\
\hline \multirow{2}{*}{ Cumarinas } & Fluorescencia & ND & ND & ND & ND \\
\hline & Ehrlich & ND & ND & ND & ND \\
\hline Lactonas terpénicas & Hidroxamato férrico & ND & ND & ND & ND \\
\hline Desoxiazúcares & Keller- Kiliani & ND & ND & ND & ND \\
\hline
\end{tabular}

ND: no detectado por el método; +: poca cantidad; ++: cantidad media; +++: abundante cantidad

et al., 2006), en ciertos tipos de cáncer (God, et al., 2007; Jung, et al., 2006), y en la reducción del estrés oxidativo del plasma y del envejecimiento (En-Qin, et al., 2010). La bioactividad de estos metabolitos va más allá de la acción medicinal, pues también se ha detectado su actividad antimicrobial y protectora de la oxidación de alimentos (Rodríguez, et al., 2007). Lo anterior daría soporte, al menos parcialmente, a algunas de las aplicaciones etnofarmacológicas empleadas por la comunidad entrevistada (alergias, brotes de piel, sarna, diabetes, etc.).

Las pruebas para la detección de saponinas y del núcleo esteroidal y terpénico coincidieron en forma notoria en las hojas de la planta (tabla 3); podría pensarse que C. leptostachyus posee saponósidos tanto de naturaleza terpénica (pentacíclicas o tetracíclicas) como esteroidal (espirostánicas), lo que sustentaría, en parte, algunos de los usos reportados por los habitantes de Gigante, consignados en la tabla 2, y que parecen coincidir en ciertos casos con la funcionalidad anteriormente descrita. Sin embargo, su aparición, principalmente en las hojas, también podría interpretarse como que hacen parte principal del sistema de defensa de la planta contra patógenos y herbívoros (Cushniea, et al., 2014; Bednarek, 2012).

Una discusión especial merecen los compuestos de naturaleza alcaloide detectados solamente en la raíz del mosquero. Este tipo de compuestos conforma uno de los grupos de metabolitos secundarios más diversos encontrados en los organismos vivos. Se ha encontrado que la gran diversidad de estructuras se corresponde con igual variabilidad de bioactividades (Arango, 2008). En la medicina se han empleado una gran cantidad de alcaloides, muchos de los cuales siguen siendo fármacos de importancia (Cholich, et al., 2005). La presencia de estos constituyentes en la raíz del mosquero podría deberse a que actúan como una herramienta de defensa de la planta en su competencia por nutrientes en suelos nutricionalmente pobres o con abundancia de patógenos (Marcano \& Hasegawa, 2002). 
En cuanto a los iridoides, considerados como monoterpenos irregulares, son parte del esqueleto de los alcaloides indólicos (Marcano \& Hasegawa, 2002). El mosquero los sintetiza en tallos y hojas, pero la raíz es el receptáculo escogido por el vegetal para depositarlos en cantidad, coincidiendo su abundancia y presencia con la de los alcaloides. Cabe mencionar que existe una serie de plantas empleadas por sus propiedades farmacológicas precisamente porque algunos de sus principios activos son de naturaleza iridoídica, entre las que se destacan la valeriana, la genciana y el noni, entre otros (Palacios, 2013). Por otra parte, los iridoides son precursores para la formación de alcaloides indolterpénicos, tales como la yohimbina, la ajmalicina, la estrictosidina, la vindolina, la catarantina, la ibogaína, la cinconamina, la quinidina y la brucina (Zhang, et al., 2014), algunas de las cuales podrían estar presentes en la raíz de la planta.

Con el ánimo de verificar esta observación, se determinó realizar una serie de pruebas cualitativas aplicando reactivos cromógenos que permitieran evidenciar el núcleo de los alcaloides predominantes en el mosquero. La tabla 4 muestra los reactivos aplicados, las coloraciones observadas y las reportadas en la literatura especializada en el tema (Kuklinski, 2000; Domínguez, 1973). Los resultados que se muestran en la tabla justifican la profundización en el discernimiento fitoquímico del mosquero, orientado fundamentalmente al conocimiento de la naturaleza química de los alcaloides que posee la planta, principalmente a nivel de la raíz.

Cabe mencionar que un gran número de medicamentos obtenido de plantas, principalmente superiores, contienen alcaloides; entre estos son de particular importancia los de núcleo indólico, los cuales son, tal vez, los que han alcanzado los niveles más altos de reconocimiento farmacológico en cuanto al material alcaloide. De gran relevancia son los de tipo bisindólico, como la vinblastina, utilizada en el tratamiento del mal de Hodgkin, y la vincristina, empleada en el tratamiento de la leucemia (Sagui, et al., 2009).

\section{Actividad antibacteriana}

Se utilizaron cepas de E. coli, K. pneumoniae, S. stiphymurium, S. aureus, para probar la bioactividad de C. leptostachyus; no se evidenció ningún efecto sobre estos organismos con los cuatro extractos (etanólico de hojas, raíz y tallo, y acuoso de hojas) en ninguna de las concentraciones ensayadas.

\section{Actividad antifúngica}

Inicialmente los extractos se probaron mediante un ensayo preliminar en el que todos se prepararon con una concentración de $10.000 \mathrm{mg} / \mathrm{l}$; los productos vegetales que mostraron la mayor actividad se seleccionaron para las pruebas más rigurosas. En ese orden de ideas, se probó la actividad de los extractos etanólicos de raíz y tallo, probados en concentraciones entre 500 y $10.000 \mathrm{mg} / \mathrm{l}$. El extracto etanólico del tallo inhibió el crecimiento de F. oxysporum en un 58,6 \% en $10.000 \mathrm{mg} / \mathrm{l}$, con una $\mathrm{CI}_{50}$ de $9.726 \pm 130 \mathrm{mg} / \mathrm{l}$, en tanto que el de raíz hizo lo propio en un $97,5 \%$ en $10.000 \mathrm{mg} / \mathrm{l}$, alcanzando una $\mathrm{CI}_{50}$ de $1.133 \pm 56,8 \mathrm{mg} / \mathrm{l}$. El ketoconazol, utilizado como control positivo, inhibió en un $100 \%$ las cepas seleccionadas en $2.000 \mathrm{mg} / \mathrm{l}$.

En A. niger los extractos etanólicos provenientes del tallo y la raíz de $C$. leptostachyus alcanzaron una $\mathrm{CI}_{50}$ de $11.883 \pm$ 1.132 y de $935 \pm 30 \mathrm{mg} / \mathrm{l}$, respectivamente, provocando daño estructural en la espora. El ketoconazol preparado en 2.000 $\mathrm{mg} / \mathrm{l}$ inhibió este mismo organismo en un $98 \%$.

Son pocos los investigadores que han incluido en sus trabajos estudios sobre C. leptostachyus; en uno de ellos, Garavito, et al., (2006), llevaron a cabo pruebas con diez especies vegetales de Colombia, entre ellas C. leptostachyus, con el fin de determinar su actividad antimalárica. Pese a que el extracto etanólico de la planta in vitro fue activo contra Plasmodium falciparum, los autores sugirieron determinar la participación de los constituyentes bioactivos en la toxicidad manifestada por la planta.

Tabla 4. Determinación de alcaloides

\begin{tabular}{lccl}
\hline Reactivo cromógeno & Observación & Valoración del resultado & Interpretación \\
\hline $\mathrm{H}_{2} \mathrm{SO}_{4}+\mathrm{K}_{2} \mathrm{Cr}_{2} \mathrm{O}_{7}$ & Precipitado verde & +++ & $\begin{array}{l}\text { El curare da color rojo a violeta; la yohimbina muestra precipitado } \\
\text { azul, violeta o verde. }\end{array}$ \\
\hline Prueba de Fröhde & Coloración azul & +++ & La yohimbina produce color azul y el curare da coloración marrón. \\
\hline Prueba de Mandelin & Coloraciones azules & +++ & $\begin{array}{l}\text { El color azul violáceo es positivo para estricnina; el color azul brillante } \\
\text { es positivo para yohimbina, y el color violeta es positivo para curare. }\end{array}$ \\
\hline FeCl $_{3}$ al $1 \%$ & $\begin{array}{c}\text { Coloración rojo- } \\
\text { anaranjado }\end{array}$ & +++ & $\begin{array}{l}\text { La morfina da azul; la heroína no desarrolla color, y la yohimbina } \\
\text { presenta coloración verde. }\end{array}$ \\
\hline Prueba de Erhlich & Coloración azul & ++ & $\begin{array}{l}\text { La presencia de compuestos con núcleo indólico se revela si se obtienen } \\
\text { coloraciones entre azul y violeta en los } 30 \text { minutos siguientes del ensayo. }\end{array}$ \\
\hline Prueba de Mecke & Precipitado verde & $\begin{array}{l}\text { La estricnina no da color; la yohimbina da coloración azul verdoso, } \\
\text { y el curare da marrón. }\end{array}$ \\
\hline
\end{tabular}


Los resultados obtenidos en la presente investigación permiten afirmar que la funcionalidad antibacteriana y antifúngica mostrada por la planta estaría asociada al conjunto de metabolitos encontrados, fundamentalmente a los de naturaleza alcaloide.

Cabe anotar que los alcaloides poseen un abanico amplio de actividades farmacológicas de gran interés terapéutico, y se distinguen porque dicha actividad es significativa en dosis bajas (Evans, 2000), por lo que no resulta extraño asociar la bioactividad manifestada por el mosquero con la funcionalidad biológica de este tipo de fitocompuestos, aunque sin menospreciar la participación de las saponinas, de naturaleza terpénica o esteroidal, y de los polifenoles, muchos de los cuales estarían en su forma glicosidada. En este contexto, es importante mencionar el aumento de patógenos resistentes a fármacos de importancia clínica y agrícola, lo que ha suscitado el interés de la comunidad farmacéutica y científica por investigar las plantas como nuevas fuentes de antimicrobianos.

\section{Conclusiones}

Esta primera aproximación a la etnobotánica del mosquero reveló la existencia de un considerable acervo cultural de tratamientos etnofarmacológicos y de recursos vegetales locales para el tratamiento de enfermedades que afectan a humanos y animales. Estos conocimientos resultan de gran utilidad de cara a nuevas tendencias productivas como la ganadería ecológica. Todos los resultados obtenidos justifican, al menos en parte, el uso etnofarmacológico de la planta por parte de la comunidad campesina de Gigante, Huila, e incentivan el interés por continuar estudiándola para ahondar en el conocimiento de esta especie vegetal, por ejemplo, para verificar el grado de toxicidad de la especie y los compuestos que la producen. La presencia de fitofenoles, saponinas triterpénicas o esteroidales, así como el contenido de material alcaloide de tipo indólico hacen prever un futuro promisorio para C. leptostachyus.

\section{Agradecimientos}

Al Departamento de Química, por el apoyo logístico, y a la Facultad de Medicina Veterinaria de la Universidad del Tolima, por el apoyo académico.

\section{Conflicto de intereses}

Los autores declaramos que no existe ningún conflicto de intereses que haya podido influir de alguna manera en la transparencia u objetividad del proceso de revisión por pares y de publicación.

\section{Bibliografía}

Alcaldía de Gigante - Huila. Sitio oficial de Gigante en Huila, Colombia. Fecha de consulta: 10 de noviembre de 2013.
Disponible en: http://www.gigante-huila.gov.co/informacion general.shtmL.

Arango Acosta, G. J. 2008. Alcaloides y compuestos nitrogenados. Facultad de Química Farmacéutica. UDEA.

Bednarek, P. 2012. Chemical warfare or modulators of defense responses - The function of secondary metabolites in plant immunity. Current Opinion in Plant Biology 15: 407-414.

Bruneton, J. 1991. Elementos de fitoquímica y de farmacognosia. Editorial Acribia. Zaragoza, España. 594 p.

Cholich, L. A., Ríos, E. J., Nelly L., Acosta, O. C. 2005. Extracción e identificación de los alcaloides de la Ipomoea fistulosa. Universidad Nacional del Nortedeste, Comunicaciones científicas y tecnológicas. 13: 1-3. Fecha de consulta: 10 de junio de 2014. Disponible en: http://www.unne.edu.ar/ unnevieja/Web/cyt/com2005/4-Veterinaria/V-013.pdf.

Cona, E. 2002. Condiciones para un buen estudio de susceptibilidad mediante test de difusión en agar. Rev. Chil Infect. 19 (2); S77-81.

Cushniea, T., Cushnie, B. \& Lambc, A. 2014. Alkaloids: An overview of their antibacterial, antibiotic-enhancing and antivirulence activities. International Journal of Antimicrobial Agents. 44: 377-386. http://dx.doi.org/10.1016/j.ijantimicag. 2014.06.001

DANE. 2005. Boletín Censo General 2005, Gigante-Huila. Fecha de consulta: 13 de noviembre de 2013. Disponible en: https://www.dane.gov.co/files/censo2005/PERFIL_PDF CG2005/41306T7T000.PDF. Domínguez, X. A. 1973. Métodos de investigación fitoquímica. Ed. Limusa. México. $281 \mathrm{p}$.

En-Qin, X., Gui-Fang, D., Ya-Jun, G., Hua-Bin, L. 2010. Biological Activities of Polyphenols from Grapes. Int. J. Mol. Sci. 11: 622-646.

Evans, W.C. 2002. Trease and Evans' Pharmacognosy, 15th ed. Saunders, Edinburgh.

Falchi, M., Bertelli, A., Scalzo, R.L., Morassut, M., Morelli, R., Das, S., Cui JH, Das DK. 2006. Comparison of cardioprotective abilities between the flesh and skin of grapes. J. Agric. Food Chem. 54: 6613-6622.

Garavito, G., Rincón, J., Arteaga, L., Hata, Y., Bourdy, G., Giménez, A., Pinzón, R., Deharo, E. 2006. Antimalarial activity of some Colombian medicinal plants. Journal of Ethnopharmacology. 107: 460-462.

Gil, R., Mejía, R., Carmona, J., Rodríguez, M. 2003. Estudio etnobotánico de algunas plantas expendidas en los herbolarios de Mérida, Ejido y Tabay (Estado MéridaVenezuela). Revista de la Facultad de Farmacia. 45 (1).

God, J.M., Tate, P \& Larcom, L.L. 2007. Anticancer effects of four varieties of muscadine grape. J. Med. Food. 10: 54-59.

Jung, K., Wallig, M. \& Singletary, K. 2006. Purple grape juice inhibits 7,12-dimethylbenz- [a]anthracene (DMBA)-induced rat mammary tumorigenesis and in vivo DMBA-DNA adduct formation. Cancer Lett. 233: 279-288. 
Kuklinski, C. 2000. Farmacognosia. Estudio de las drogas y sustancias medicamentosas de origen natural. Ed. Omega. Barcelona, p. 528.

Lock de Ugaz, O. 1994. Investigación fitoquímica, Métodos en el estudio de productos naturales. Segunda Edición. Fondo Editorial de la Pontificia Universidad Católica del Perú. $300 \mathrm{pp}$.

Mansaray, M. 2000. Herbal remedies: Food or medicine? Chemistry and lndustry. 20: 677-678.

Marcano, D. \& Hasegawa, M. 2002. Fitoquímica orgánica. Consejo de Desarrollo Científico y Humanístico, Universidad Central de Venezuela. 588 pp.

Palacios, M. 2013. Texto digital de farmacognosia y fitoquímica. Universidad Católica Los Angeles de Chimbote. Fecha de consulta: 10 de junio de 2014. Disponible en: http:// www.academia.edu/5271729/UNIVERSIDAD CATOLICA LOS ANGELES DE CHIMBOTE FACULTAD DE CIENCIAS_DE_LA_SALUD_ESCUELA_PROFESIONAL DE FARMCIA Y BIOQUIMICA TEXTO DIGITAL DE FARMACOGNOSIA Y FITOQUIMICA.

Pardo, M. \& Gómez, E. 2003. Etnobotánica: aprovechamiento tradicional de plantas y patrimonio cultural. Anales del Jardín Botánico de Madrid. 60 (1).

Red Nacional de Jardines Botánicos. 2008. Fichas de especies de plantas útiles de los jardines botánicos de Colombia Kunth. Fecha de consulta: 3 de noviembre de 2013. Disponible en: http://www.biodiversidad.co/ficha/id/1801.

Rodríguez-Echeverri, J.J. 2010. Uso y manejo tradicional de plantas medicinales y mágicas en el valle de Sibundoy, Alto Putumayo, y su relación con procesos locales de construcción ambiental. Rev. Acad. Colomb. Cienc. 34 (132): 309-326.

Rodríguez-Vaquero, M.J., Alberto, M.R. \& Manca-de-Nadra, M.C. 2007. Antibacterial effect of phenolic compounds from different wines. Food Control. 18: 93-101.
Rosado-Aguilar, J.A., Aguilar-Caballero, A.J., RodríguezVivas, R.I., Borges-Argaez, R., García-Vázquez, Z., Méndez-González, M., Cáceres-Farfán M., DorantesEuán, A. 2008. Actividad ixodicida de extractos crudos de Diospyros anisandra contra larvas de Rhipicephalus (Boophilus) microplus (Acari: ixodidae). Tropical and Subtropical Agroecosystems. 8 (3): 297-301.

Sagui, F., Chirivı, C., Fontana, G., Nicotra, S., Passarella, D., Riva, S., Danieli, B. 2009. Laccase-catalyzed coupling of catharanthine and vindoline: An efficient approach to the bisindole alkaloid anhydrovinblastine. Tetrahedron. 65: 312-317.

Sanabria, G. A. 1983. Análisis fitoquímico preliminar: metodología y su aplicación en la evaluación de cuarenta plantas de la familia Compositae. Universidad Nacional de Colombia. Facultad de ciencias. Departamento de Farmacia. Santafé de Bogotá. 77 p.

Shanmuganayagam, D., Warner, T.F., Krueger, C.G., Reed, J.D., Folts, J.D. 2007. Concord grape juice attenuates platelet aggregation, serum cholesterol and development of atheroma in hypercholesterolemic rabbits. Atherosclerosis. 190: $135-142$.

Torres, N. 2005. Métodos para la detección de resistencia a los antimicóticos. Infectio. 9 (4).

Vàlles, J. 1996. Los nombres populares de las plantas: método y objetivo en etnobotánica. Monograf. Jard. Bot. Córdoba. 3: 7-14.

Weckesser, K., Engel, B., Simon-Haarhaus, A., Wittmer, K., Pelz, C.M. 2007. Screening of plant extracts for antimicrobial activity against bacteria and yeasts with dermatological relevance. Phytomedicine. 14: 508-516.

World Health Organization. 1998. Quality control methods for medicinal plant material. Ed. World Health Organization. Geneva, Switzerland. 115 p.

Zang, D., Chen, J., Zang, L., Song, Q., Gao, K. 2014. Bioactive alkaloids from Palhinhaea cernua. Phytochemistry letters. 10: 76-79. 